\title{
Las redes sociales como herramienta de difusión y prevención del microtráfico
} en el Ecuador

\section{Social networks as a tool for the dissemination and prevention of microtrafficking in Ecuador}

\author{
Marco Patricio Villa-Zura \\ ui.marcovilla@uniandes.edu.ec \\ Universidad Regional Autónoma de los Andes, Ibarra \\ Ecuador \\ https://orcid.org/0000-0001-5248-0032 \\ Naghely Noboa-Benavides \\ di.naghelylnb44@uniandes.edu.ec \\ Universidad Regional Autónoma de los Andes, Ibarra \\ Ecuador \\ https://orcid.org/0000-0002-3211-0330 \\ Tapia Miguel-Montenegro \\ di.miguelamt52@uniandes.edu.ec \\ Universidad Regional Autónoma de los Andes, Ibarra \\ Ecuador \\ https://orcid.org/0000-0001-5243-2639
}

Recepción: 15 de septiembre 2021

Revisado: 25 octubre 2021

Aprobación: 15 de noviembre 2021

Publicación: 01 de diciembre 2021 


\section{Estimado Editor (a):}

El microtráfico en la actualidad ha acarreado problemas en el entorno social del Ecuador, debido a que se ha podido identificar un incremento en la oferta y demanda de sustancias estupefacientes sujetas a fiscalización, mismas que se dan a raíz de una tasa elevada de familias disfuncionales, falta de oportunidades laborales, pobreza y necesidad extrema, y el mal contenido que circula en redes sociales; de ello se desprende que la población joven es uno de los grupos más vulnerables en cuanto a micro tráfico se refiere, por ende su entorno familiar, educativo y social se ve afectado directa e indirectamente por esta problemática.

El incremento de esta problemática tuvo su auge a inicios de la crisis sanitaria (COVID19), sucedida a nivel global, la cual se ha mantenido y presenta un crecimiento paulatino, afectando de esta manera a la clase obrera, misma que ha visto al micro tráfico como un medio acomodaticio para la estabilidad e incremento de su situación económica. Como principales consecuencias se pueden observar:

1. Presencia de un incremento en la tasa de delincuencia;

2. Acumulación de privados de libertad en las cárceles del Ecuador;

3. Incremento de violencia intrafamiliar; y

4. Deterioro parcial o total de la salud de los involucrados.

En este sentido, la ley ecuatoriana referente al microtráfico presenta una clara permisividad respecto a la tenencia de sustancias estupefacientes sujetas a fiscalización, mencionada en el artículo 220 del Código Orgánico Integral Penal (COIP), misma que ha generado un incremento en la demanda de este tipo de sustancias por parte de sus consumidores, permitiendo que aumente su elaboración y comercialización a pequeña escala, expandiéndose desde las zonas urbanas hacia las rurales del país.

Así mismo, el uso moderno de las redes sociales se muestra como un medio de gran influencia en especial para la juventud ecuatoriana, de este se ha obtenido grandes beneficios como desventajas, según el manejo que se le dé a las mismas al momento de difundir información y contenido referente a la venta y consumo de sustancias 
estupefacientes. Paralelamente, en los dos últimos años como consecuencia del constante encierro, el uso de estos medios ha ido en aumento, por lo que las personas han adoptado su uso como parte de su rutina. Las redes sociales como herramienta de educación representan un beneficio, educando a la población sobre la problemática y con la expectativa de prevenirla. Sin embargo, hay quienes las manejan como una herramienta para desinformar acerca de la realidad, buscando maquillarla, con el fin de inmiscuir a más personas en este entorno.

Por lo tanto, el microtráfico es un problema social ya que, no solo afecta a los consumidores y a los micros traficantes, sino también a las personas que se encuentran en su entorno como lo son sus familiares, sus amigos y vecinos. El problema del microtráfico ha ido aumentando en los últimos años y ha influenciado tanto a jóvenes como a adultos, los cuales no conocen el riesgo de comercializar este tipo de sustancias y si los conocen, no le prestan ni el más mínimo interés. El comercializar con sustancias sujetas a fiscalización eleva de cierta manera la delincuencia, ya que es una guerra continua entre micro traficantes por mantener su territorio.

En el Ecuador, el microtráfico se ha expandido por las principales ciudades y de a poco se sigue esparciendo por sus alrededores; el país se encuentra aún más vulnerable, ya que con la permisividad de las leyes, la pobreza y la pérdida de empleos por motivos del covid-19, las personas optan por obtener ingresos de manera urgente e inmediata, esto siendo en el caso de necesidad, ya que otros optan por dejar sus empleos con sueldo moderado para conseguir un mayor ingreso y con poco esfuerzo, esto es lo que se palpa a diario en el país.

Sin embargo, la permisividad legal con respecto al microtráfico se ha ido manifestando con el paso del tiempo en mayor proporción; el artículo 220 del Código Orgánico Integral Penal (2014), establece las diferentes penas para la tenencia en sus respectivas medidas permitidas por la ley. La flexibilidad legal se ha mantenido, pese a las diferentes reformas y cambios realizados, los cuales han ocurrido de manera casi indetectable; pero que, con la acumulación de lagunas presentes en las leyes, ha desembocado en un incremento del microtráfico. 
El 13 de Agosto de 2020 se realizó la promulgación de la Ley Orgánica Contra el Consumo y Microtráfico de Drogas en la que se aprobaron reformas respecto a la tenencia y tráfico de sustancias estupefacientes, las cuales aún se pueden considerar como sujetas a fiscalización pero solo de forma, esto se puede verificar en la tabla de tenencia de sustancias estupefacientes para consumo propio, en la cual se menciona la cantidad máxima de tenencia para una persona, esta situación no tendría ninguna respuesta a las regulaciones establecidas, pero la Ley Orgánica de la Salud en su artículo 51 establece que esta tendencia puede justificarse si es para consumo propio y medicinal; escenario que ha fomentado al microtráfico y la falsificación de certificados médicos, afirmando el padecimiento de enfermedades tales como Glaucoma u otras que necesitan su consumo.

En la Ley Contra el Consumo y Microtráfico de Drogas en el artículo 8 refiere a que: el Estado debe ejecutar programas de prevención y atención con el aprovechamiento de la Tecnología de la Información y Comunicación, los cuales corresponden a los Gobiernos Autónomos Descentralizados, mismos que están expuestos en la Ley, donde se tratan temas contra el uso, consumo y tráfico de sustancias ilícitas sujetas a fiscalización; con el fin de mejorar la salud pública, la seguridad ciudadana, la productividad, la educación, entre otros.

Por tanto, es responsabilidad del Estado ecuatoriano garantizar la planificación de programas de prevención y atención para preservar la salud e integridad de los ciudadanos, de igual manera se involucran los organismos de Estado e instituciones necesarias del ámbito de su competencia, para verificar que las políticas públicas creadas estén siendo ejecutadas y se cumplan los objetivos previstos. El impacto económico que causa la pandemia en el Ecuador prevé estragos para la sostenibilidad financiera, esto ha dejado familias sin el sustento diario, personas que viven de lo que logran vender en sus pequeños negocios, sinnúmero de desempleados a raíz de que sus empleadores quebraron en sus negocios, provocando una incertidumbre en la sociedad, lo que los lleva a tomar medidas de supervivencia drásticas.

Es así como las circunstancias impulsan a que más personas se motiven a comercializar sustancias estupefacientes, lo cual resulta de la afección en la calidad 
de vida. El uso de las redes sociales y la integración de las tecnologías de la información y la comunicación (TICs), según Prensky (2013) sirven como una alternativa de enseñanza para brindar información a un colectivo como son los nativos digitales, es decir, los educandos y educadores del siglo XXI, de una manera más atractiva y efectiva en la era actual. No obstante, al haberse creado con diferentes fines, y con lo que respecta a lo mencionado por Sanchez, Schmidt, Zuntini y Obiol (2017), el uso de redes sociales para la transferencia de información resulta muchas veces inadecuada o utilizado de manera ineficiente, inhabilitando a las futuras generaciones. En la sociedad actual las redes sociales representan el medio de información, noticias y conocimiento más utilizado por la humanidad, en general los instrumentos que son compartidos en estas van desde aspectos de la vida diaria hasta cadenas informativas, las cuales llegan a manos de los diferentes usuarios de estas redes. Molina y Toledo (2014) mencionan que cada cosa que se exprese a través de las redes sociales suele tener un efecto positivo o negativo en los usuarios (p. 30). Esto logra determinar que cualquier cosa, imagen, mensaje y/o noticia que sea compartida en alguna red social tiene cierta influencia sobre los usuarios y un mayor porcentaje de esta en grupos más vulnerables como es la adolescencia de la Nación, la cual representa a los usuarios más constantes de las mismas.

En la actualidad el internet ha sido un medio que ha beneficiado a la población del Ecuador, ha servido como una herramienta de trabajo, estudio, comunicación y entretenimiento. Las redes sociales son un medio masivo de comunicación donde tiene acceso la mayoría de las personas. La comunicación instantánea, las oportunidades de trabajo, compartir conocimientos y entretenimiento son beneficios que acarrean estas redes, donde se obtiene y se transmite información y donde se pueden realizar campañas o programas de prevención y atención contra el microtráfico.

En consecuencia, de la familiarización con las redes sociales, tenemos que muchas veces la información que estás circula es falsa, es medianamente verdadera y lo más común es que se trata de normalizar actos ilegales como el microtráfico, que moral, ética y legalmente están mal, se determina que la población joven al no tener el control 
debido de sus progenitores, son los más propensos a ser influenciados y dar paso a comportamientos delictivos.

Por lo tanto, las redes sociales son una herramienta de comunicación que tiene una gran influencia en la población ecuatoriana, de manera que se las puede considerar imprescindibles al momento de informar o desinformar sobre una problemática del microtráfico. Así mismo, han transmitido información acerca de la incertidumbre que propagó la incidencia del covid-19 y los efectos incrementados sobre la actividad lícita del microtráfico como consecuencia del decreciente factor económico a nivel Mundial y Nacional.

\section{FINANCIAMIENTO}

No monetario.

\section{AGRADECIMIENTO}

A la Universidad Regional Autónoma de los Andes, Ibarra, por motivar el desarrollo de la Investigación.

\section{REFERENCIAS CONSULTADAS}

Asamblea Nacional Constituyente de la República del Ecuador, (2008). Constitución de la República del Ecuador. [Constitution of the Republic of Ecuador]. Montecristi. Registro Oficial 449 de 20-oct-2008. Recuperado de https://n9.cl/sia

Asamblea Nacional República del Ecuador. (2020). Ley orgánica contra el consumo y microtráfico de drogas. [Organic Law against drug consumption and microtrafficking]. Registro Oficial o suplemento $\mathrm{N}^{\circ} 266$. Recuperado de: https://n9.cl/4j9lv

Asamblea Nacional República del Ecuador (2014). Código Orgánico Integral Penal. [Organic Comprehensive Criminal Code]. Registro Oficial Suplemento 180 de 10-feb.-2014.Recuperado de: https://n9.cl/g6sc

Congreso Nacional (2006). Ley Orgánica de la Salud. [Organic Law of Health]. Registro Oficial Suplemento 423 de 22-dic.-2006. Ley 67. Última modificación: 18-dic.-2015. Recuperado de: $\underline{\text { https: } / / \mathrm{h} 9 . \mathrm{cl} / 4 \mathrm{kfc}}$ 
Molina, G. y Toledo, R. (2014). Las redes sociales y su influencia en el comportamiento de los adolescentes. [Social networks and their influence on the behavior of adolescents]. Universidad del Azuay. Cuenca, Ecuador.

Pensky, M. (2013). Enseñar a nativos digitales. Una propuesta pedagógica para la sociedad del conocimiento. [Teach digital natives. A pedagogical proposal for the knowledge society]. Prólogo de Stephen Heppell. Academia. edu. Consultado el 23 de junio de 2021.Recuperado de: https://n9.cl/vgoud

Sanchez, M. A., Schmidt, M. A., Zuntini, J. I. y Obiol, L. (2017). La influencia de las redes sociales virtuales en la difusión de Información y conocimiento: estudio de pymes. [The influence of virtual social networks on the dissemination of information and knowledge: study of SMEs]. Revista Ibero Americana de Estrategia. Recuperado de: https://n9.cl/nadc9 